\title{
Requirements Engineering for a Matching Algorithm to Use in Hospital Networks
}

\author{
Hubertus Franke ${ }^{1 *}$, Martina Hasseler ${ }^{2}$, Denise Dick ${ }^{1}$, Stephanie Krebs ${ }^{1}$ \\ ${ }^{1}$ Institute for Logistics Optimization, Ostfalia, University of Applied Sciences, Salzgitter, Germany \\ ${ }^{2}$ Faculty of Public Health Services, Ostfalia, University of Applied Sciences, Wolfsburg, Germany \\ *Corresponding author: Tel: +49 (0)5341 / 875 -51610; email: hu.franke@ostfalia.de \\ Manuscript submitted November 28, 2017; accepted May 12, 2018. \\ doi: 10.17706/jsw.13.8.414-420
}

\begin{abstract}
This paper shows the opportunity to optimize the personnel selection procedures in hospitals for short-dated proxies in need of the skills shortages. The basis for this optimizing is an algorithm for matching parameters which help to bring firms and employees with needed skills together.
\end{abstract}

Key words: Algorithm, hospital, network.

\section{Introduction}

In Germany, the human resource management has growing difficulties in filling current job vacancies, especially for care activities. Less and less employees take care of an increasing number of patients for 365 days a year in shift work. Hospital wards must be staffed with sufficient qualified personnel to guarantee high quality care for patients [1]. Staff shortages allocated as result of short term absentees of workers will be enforced by the shortage of skilled professionals in health care.

For duty scheduling these problems mean an increasing complexity. In compliance with statutory regulations it is very difficult to fill these shifts with employees from its own ranks [2]. A manual planning is very time-consuming so there are different software tools for time planning support. But these planning tools are not able to give a solution to the problem of staff shortage.

In this paper, a concept of a software should be introduced which is linked to a recruitment agency. Via this agency the hospital can request more staff to fill in the gaps of working schedule. A so-called human resources pool is to be realized in information technology to simplify this process. The publication focused on staff requisition and the required matching algorithm.

\section{Presentation of the Problem}

Hospitals are more and more frequently reliant on changing shifts on a short term which effect a manual intervention at the working schedule. At this point the hospitals exploit increasingly the services of employment agencies [3], which require a major administrative burden. In part, there are some software products to support the process of work scheduling but still, the process of staff requisition is not adequately reflected by this software.

This paper provides an initial concept of a software product, that was to make it possible to request additional employees via a shared database or a staff pool from an extern recruiting service to support their own staff for a selecting period. It is important to create a requirements profile for the necessary qualifications which new employees must bring with them.

To find the adequate candidate of a selection by several employees an algorithm should be implemented which compares the existing qualifications of the employees with the requirements placed on the clinic and leave a list of workers who fulfill the requirements to choose from it. This publication shows how such an algorithm can be 
implemented in a software for personnel planning.

\section{State of Research}

The use of algorithms to recognize similarities in user profiles was exploited for the first time in dating agencies. In the last few years, this technology found its way into the human resource management of companies for recruitment of applicants [4]. Therefore, it can be concluded that it is possible that a software for personnel placement can benefit directly by using a similar algorithm.

The choice of partner in professional or personal way is defined by finding a person who fits perfectly with their characteristics by oneself or in this company. Dating services identify matches between two people based on personality tests which should be filled out by both sides. This frequently consists questions in the high double-digit range and after filling the form it will be assessed with Matching points. These would be calculated against each other and yield a scoring. The better the scoring, the better the matching [5]. That is the simplest version of matching. It can be extended by implement a plurality of criteria to influence the selection.

In recruiting the algorithms are used to sort the candidates so that the personnel manager only gets the possible employees suggested [6]. This proceeding can be broadened so that the algorithm locates the best candidate and propose this employee to the personnel manager.

This concept can be taken over for a personnel placement in the care sector. The algorithm must be written in a way that finds the similarities between qualifications and requirements and sort the employees by the frequency of matches.

\section{Conception}

For the implementation of the algorithm for needs of the staff requisition should be create a stable foundation for the software. It would be a benefit for user if the staff requisition is implemented in a human resource software with work scheduling and time registration. On this occasion, there are synergy effects because the gaps in the roster can be seen and directly request for increase with workers from recruitment agencies.

An automated shift planning can relieve nursing management. Through the setting of legal restrictions, the services can be planned so that every staff member should work nothing more, but also nothing less than what is stated in the employment agreement. Overtime hours can be generally minimized which result in a reduction of free days and shortages of staff. This relation can be depicted graphically as follows.

Every gap which is resulted by this process can be displayed and closed by the request of employees over a staff requisition. A suitable methodical for this request is a form in which all necessary information can be signed in. In this case, necessary information is the time span for engagement, the hospital ward where the employee will be deployed and the qualifications which he or she should bring with them.

Last ones are important for the matching of qualifications and requirements which is the heart of the software.

\section{Matching}

The matching serves to compare the request of the hospital with the qualifications of the employees. The aim of this is to display a list of employees which fulfill one or more requests. Accordingly, the best employee for this shift gap is the one with the most matches. A sorting of the list should be in descending order so that the best employee is placed at the very top of the list. This relation can be depicted graphically as follows.

The blue circles stand for the employees, each circle for one employee. The green ones stand for each qualification and the grey circle represent the request of the hospital.

In Fig. 1 can be seen every connection between the request, the qualifications and the employees. The qualifications form the interface between employees and request. Not every employee has every qualification and not all the employee qualifications are necessary listed. Similarly, not every listed qualification is requested from the hospital.

The task of the matching algorithm is to find out the connection between every employee with the request of 
the hospital and display the quantity of similarities. In modified variants, a possibility to weighting the requested qualifications can be implemented. Therefore, the hospital can decide which qualification is part of the necessary conditions. Employees who does not comply these conditions will be sorted out.

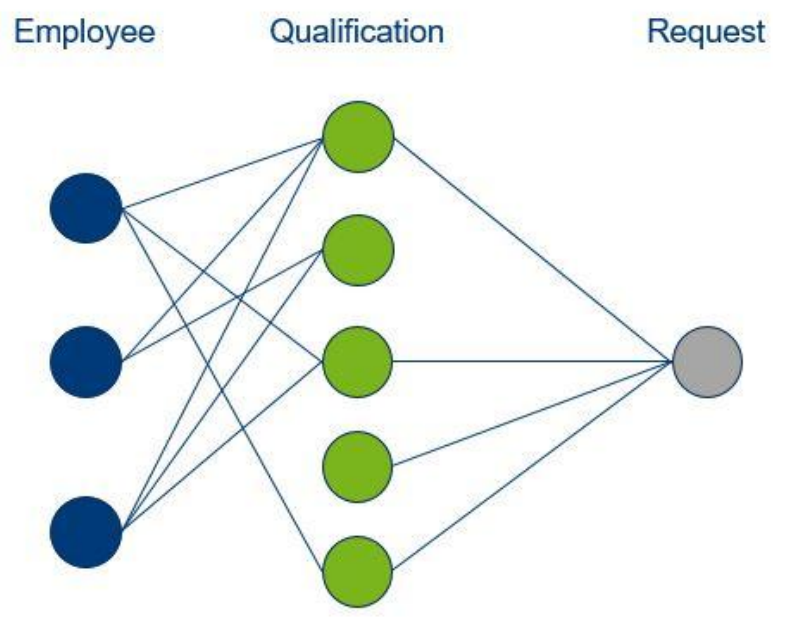

Fig. 1. Graphic relation between qualification and request.

\section{Algorithm}

The formal specification of the problem:

Let $R$ be the set of Requirements (Requests) of skills in nursery

Let $\mathrm{Q}$ be the set of (Requirements-) Qualifications in nursery

Let $\mathrm{E}$ be the set of Employees who will be required in nursery

Let $\mathrm{EQ}$ be the set of qualifications of an employee to fulfill a requirement $\forall \mathrm{m} \epsilon \mathrm{E}$

Let RQ be the set of requirements-qualifications of an employee, who can fulfill the requirements

With

$$
\begin{array}{llll}
\mathrm{R}=\left\{\mathrm{r}_{1}, \ldots, \mathrm{r}_{\mathrm{m}}\right\} & \Lambda & |\mathrm{A}|=\mathrm{m} ; \\
\mathrm{Q}=\left\{\mathrm{q}_{1}, \ldots, \mathrm{q}_{\mathrm{n}}\right\} & \Lambda & |\mathrm{Q}|=\mathrm{n} ; \\
\mathrm{E}=\left\{\mathrm{e}_{1}, \ldots, \mathrm{e}_{\mathrm{k}}\right\} & \Lambda & |\mathrm{A}|=\mathrm{k} ;
\end{array}
$$

Fig. 2. Formal specification of the basic data.

The result of this formal basic data-specification will be shown in the next figure.

$$
\begin{gathered}
\forall \mathrm{r} \in \mathrm{R}: \exists \mathrm{RQ}=\left\{\mathrm{rq}_{1}, . ., \mathrm{rq}_{\mathrm{s}}\right\} \quad \Lambda \quad|\mathrm{RQ}|=\mathrm{s} \quad \Lambda \\
(\mathrm{RQ} \subseteq \mathrm{Q}) \Lambda(\mathrm{Q} \cap \mathrm{RQ}) \neq \square: \sum \mathrm{Q}(\mathrm{r})=\mathrm{RQ} \\
\forall \mathrm{e} \in \mathrm{E}: \exists \mathrm{EQ}=\left\{\mathrm{eq}_{1}, . ., \mathrm{eq}_{\mathrm{t}}\right\} \quad \Lambda \quad|\mathrm{EQ}|=\mathrm{t} \quad \Lambda \\
(\mathrm{EQ} \subseteq \mathrm{Q}) \Lambda(\mathrm{Q} \cap \mathrm{EQ}) \neq \square: \sum \mathrm{Q}(\mathrm{e})=\mathrm{EQ}
\end{gathered}
$$

Fig. 3. Formal specification of the dynamic data 
1. Compute $R Q$ with $(R Q \subseteq Q)$ and $\sum$ Qualification(r) $=\mathrm{RQ}$

2. Compute $\mathrm{EQ}$ with $(\mathrm{EQ} \subseteq \mathrm{Q})$

3. Choose $e^{*} \in \mathrm{E}:\left|\mathrm{EQ}\left(\mathrm{e}^{*}\right)\right|=\max ! ! !$

Fig. 4. Algorithm.

The algorithm in Fig. 4 solves the problem with an easy manner. In real scenarios, a more realistic algorithm is much more sophisticated.

After running this algorithm, the user receives a list of potential employees with an accordance of at least one qualification. The algorithm sort all those people out of the list, who have not even one requested qualification. To issue a result at all, there should be the condition, that every possible employee with complied qualifications is available for selection.

The following fig. 5 demonstrates a possible data structure for the algorithm using in fig. 4. Employees are the main structure elements in the system. The employees are in relation to $E=\{e 1, \ldots, e k\} \quad \Lambda \quad|E|=k$ in line (3) in fig. 2. Here every employee has a possible amount of qualifications in the structure EQ ("qualifications of an employee"). This is in relation to $\sum \mathrm{Q}(\mathrm{e})=\mathrm{EQ}$ in line (5) of fig. 3. The qualifications are in relation to $\mathrm{Q}=\{\mathrm{q} 1, \ldots, \mathrm{qn}\}$ $\Lambda|\mathrm{Q}|=\mathrm{n}$ in line (2) in Fig. 2.

The requirements are in relation to $\mathrm{R}=\{\mathrm{r} 1, \ldots, \mathrm{rm}\} \quad \Lambda \quad|\mathrm{A}|=\mathrm{m}$ in line (1) in fig. 2. Last not least the "Requirements-Qualifications" are in relation to RQ in line (4) of fig. 3.

Fig. 3 shows the relations between the sets R, Q and E. The graphical view as an Entity-Relationship-Model is shown in fig. 5

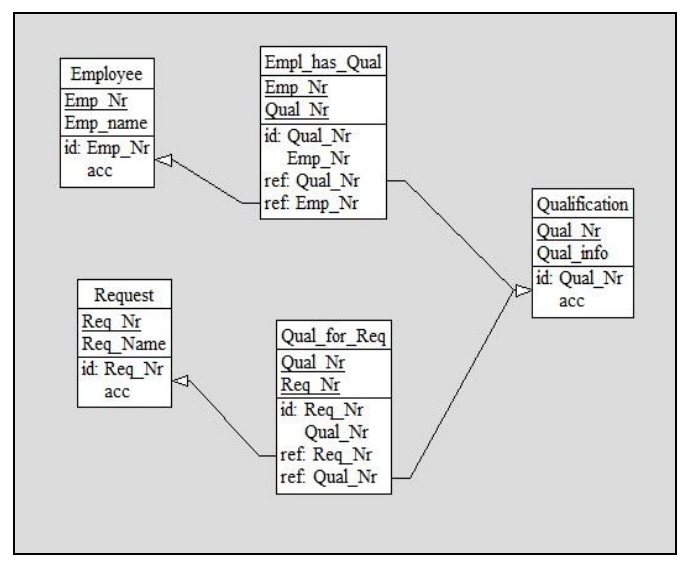

Fig. 5. Data structure.

The matching-algorithm of all emplyees with all qualifications in all request is a natural join on all tables of fig. 5 if you use a relational database with sql as a structured query language. The sql on all table will be:

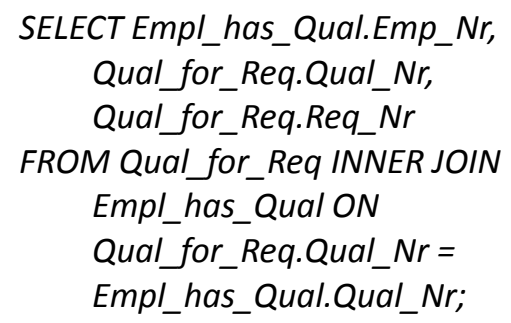

Fig. 6. SQL expanded 
Unfortunately, this sql is about all tables and the performance of the sql is not optimized. Thus, a smaller and more performant sql is more intelligent. Here, we use an sql only using the tables Empl_has_Qual and Qual_for_Req, which are described as RQ and EQ in Fig. 4.

A possible result as an example is in Fig. 7.

This algorithm mentioned in Fig. 4 and described as a data structure in fig. 6 and fig. 7 is the basic algorithm to solve several more sophisticated problem situations, which are mentioned in chapter 2 . The following example will help us to understand the algorithm and the data structure.

\section{Example}

The algorithm mentioned in the previous section shall here be explained in a short example. For the scenario, a fictitious clinic would be taken as a starting point.

The software product described in this work is used in this fictitious hospital.

During the monthly automatic planning, not all shifts at the hospital ward No.1 could be filled. Also, a manual intervention brought no enhancement of the situation. Thus, the Nursery management had the task to request more employees by a personnel service provider.

The following graphic shows that the personnel service provider can offer three employees for the requested period. These employees have for example the numbers 1, 2 and 3. For the request, the hospital could choose between the five qualifications $a, b, c, d$ and e.

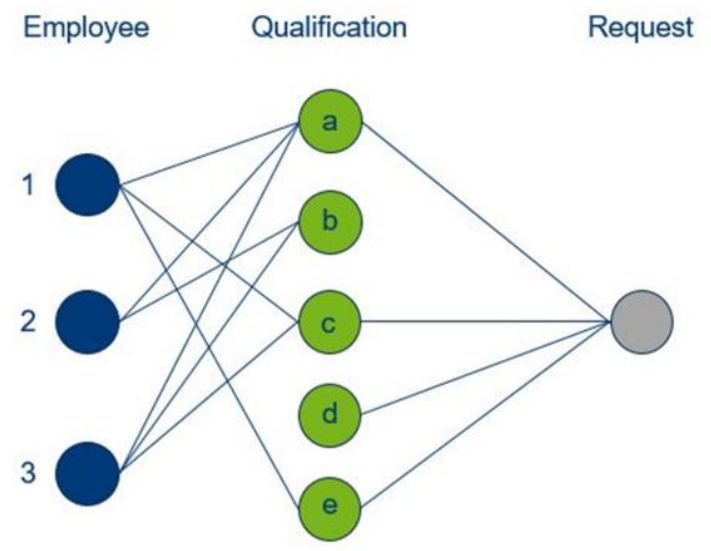

Fig. 7. Example A.

In this example, the hospital has chosen the qualification a, $c, d$ and e. Only qualification b is not wanted. The software runs the algorithm and compare all chosen qualifications with the properties of these possible employees. Fig. 5 depict, that qualification a is fulfilled by all the employees. From this follows that each of the employees will be listed on the output list, because only one match is enough for listing.

The next qualification of request is qualification c which is only complied by Employee 1 and 3. Thus Employee 2 is namely listed but have been placed lowest in the ranking because the other employees fulfill more requested properties. While qualification $\mathrm{d}$ has no relationship to any of these possible employees, qualification e can be associate to Employee 1.

The output sequence is as follows:

1. Employee 13 of 4 qualifications fulfilled

2. Employee 32 of 4 qualifications fulfilled

3. Employee 21 of 4 qualifications fulfilled

The nursing service can now decide and without any further influence of environmental variables they will choose Employee 1 to request.

In practice, it frequently occurs that some properties are more highly rated than others. This process should 
be implemented in this algorithm for hospital employee matching. Some of the qualifications are really needed and other ones are nice to have but not necessary. The following example shows such a situation.

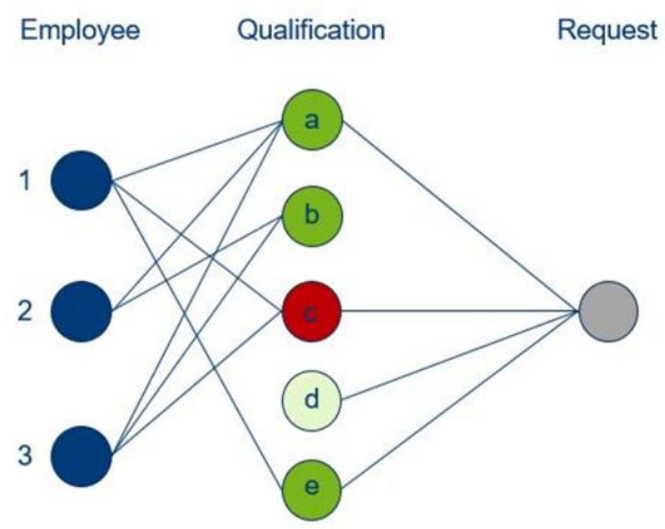

Fig. 8. Example B.

In Fig. 8, the hospital has indicated qualification c as strictly necessary, whereas the qualification $\mathrm{d}$ is optional. These differences are highlighted in different colour, the necessary qualification $c$ in red and the optional qualification d in light green.

The algorithm will start the same way as in the previous example but this time the node $\mathrm{c}$ is considered first. Thereby the Employee 2 is removed from the possible candidates because of not fulfill the necessary request qualification. Employee 1 and Employee 3 possess the necessary property and will be listed in result output.

After the look at qualification $\mathrm{c}$ the other requested qualifications must be taken under consideration as shown in the previous example. The output shows the employees in following order:

1. Employee 13 of 4 qualification necessary conditions fulfilled

2. Employee 32 of 4 qualification necessary conditions fulfilled

In this scenario too, the nursery service would choose Employee 1 but this time, there is only one alternative solution.

\section{Conclusion}

This publication points out that the use of Matching algorithm is a worthwhile investment for hospitals cooperating with personnel service providers. Administrative tasks could be simplified and the nursery service can handle their work better and in a more efficient way. The work scheduling can be automated and the short-term recruitment will significantly be simplified and speeded-up. Manual action is seldom required and time can be redirected to more important works.

In view of the progressive digitalization and the shortage of skilled professionals this software would be a good solution to solve existing problems being understaffed with a digital software product for work scheduling and directly communication.

\section{References}

[1] Weskamm, A. (2016). Dienstplanung im krankenhaus. Deutscher Berufsverband für Pflegeberufe e.V. (DBfK), Sammelband zur DBfK-Aktion Mein Recht auf Frei! (p. 6), Berlin.

[2] König, J., \& Raiß, M. (2015). Dienstplangestaltung - Was Pflegekräfte wissen müssen. Ein Ratgeber für die tägliche Praxis. (pp. 50 - 70), Hannover: Schlütersche (Pflege-Kolleg).

[3] Bräutigam, C., Dahlbeck, E., Enste, P., Evans, M., \& Hilbert, J. (2010). Flexibilisierung und Leiharbeit in der 
Pflege (Arbeitspapier 215) (p. 5). Düsseldorf: Hans Böckler Stiftung.

[4] Winzenried, S. (2015). HR und Leadership, Was bedeutet eigentlich genau Job- bzw. Skills-Matching? In der Rekruitierung und im HR-Management?: Teil 2/10. Website of Kalaidos Fachhochschule Zurich. Retrieved from the

Website: https://www.kalaidos-fh.ch/de-CH/Blogs/Posts/2015/06/was-bedeutet-eigentlich-genau-job-bzw-skillsmatching-in-der-rekrutierung-und-im-hr-management-teil-210.

[5] Persis GmbH. (2017). Matching: Definition, Funktionen und Einsatz. Retrieved from the Website: https://www.persis.de/aktuell/2017/matching-bewerbermanagement.html

[6] Softgarden e-recruiting GmbH (2015). Matching-Technologien: Allzweckwaffe in der Bewerberauswahl?. Retrieved from the Website: https://www.softgarden.de/matching-technologien-bewerberauswahl/.

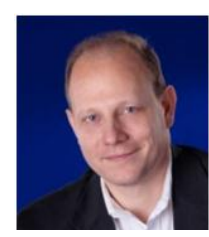

Hubertus Franke is professor for logistics and information management at the Ostfalia University of Applied Sciences

Before that, he had professorships in Hesse, Thuringia and Saxony-Anhalt and worked as senior manager in several industrial companies. He is operating as head of the Institute for Logistics Optimization at the Ostfalia - University of Applied Sciences, since 2013. Furthermore, he teaches in various courses and study programs of logistics and computer sciences in Salzgitter/Germany. Since 2017, he is leading research projects of "Information Technology in Hospital Networks". Dr. Franke focused his research and publication activities on information technology, logistics and decentralized supply chain management. Especially the sustainable development of logistics in healthcare is one of his favorite research areas.

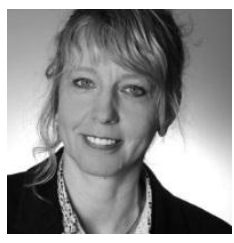

Martina Hasseler is with University of Heidelberg, Faculty of Medicine, head of program interprofessional health care. Research activities with emphasis on: "High quality health and nursing care through systematic findings and improvements of framework conditions in health and nursing care as well as interprofessional and setting spanning cooperation and qualification of health and nursing care professions." Research activities in following areas - health and nursing care of vulnerable population groups - framework conditions of health and nursing care (coordination and integrated health care) - interprofessional cooperation as well as education, further education, qualification.

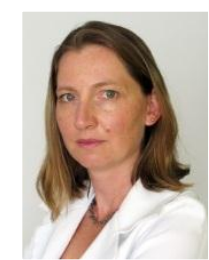

Denise Dick is with Ostfalia - University of Applied Sciences and she is a M.Sc. denise dick is working at the Ostfalia - University of Applied Sciences since 2009 as trainer in software development using the java programming language and since 2017 as research assistant and PhD-student, working on the research project "Information Technology in Hospital Networks". Her research expertise focus on matching algorithms in healthcare context and in hospital networks. Before that, she worked as software developer and system analyst in several companies in Brazil and Germany.

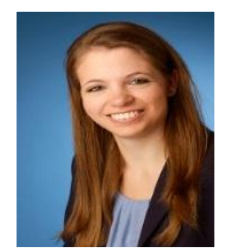

Stephanie Krebs is with Ostfalia - University of Applied Sciences. Stephanie Krebs M. Sc. is working as research-assistant and a PhD-student at the Ostfalia University of Applied Sciences. Her research area is hospital-networking in healthcare.

From 2009 until 2015 she studied Biology and German linguistics (B.A.) at Ruhr University Bochum and economics at Friedrich-Schiller University Jena. After that she was employed in various companies as Executive Assistant, in Human Recourse Management Departments and Hospital Management. Furthermore she takes part in different advanced training programs of Human Resource Development and Training. Her research expertise focuses on Human Resource Development and Innovations. 